\title{
Arguments in University-Level Debating: Subjective or Objective
}

\author{
Ignasia Yuyun \& Siegfrieda A. S. Mursita Putri \\ Universitas Kristen Krida Wacana (UKRIDA), Jakarta \\ ignasia_y@ukrida.ac.id \& siegfrieda@ukrida.ac.id
}

\begin{abstract}
This article reports a study on subjectivity and objectivity of arguments in university-level debating. This study aims to identify the level of subjectivity and objectivity of arguments in debating. Employing mainly a qualitative method focusing on discourse, the study took a recorded 2015 National University Debating Championship in Kopertis 3 Jakarta with British Parliamentary debating system as the source of data. Hallidayan's modality analysis was the basis of the analysis. The use of orientation and manifestation of modality and modality metaphor were analyzed to reveal the level of subjectivity and objectivity among debaters in university-level debating. At last, the study shows the dominant use of explicit subjective modality in delivering arguments. This tendency implies that debaters prominently express their points of view to the debate.
\end{abstract}

Keywords: argument, modality, objectivity, university-level debating, subjectivity

\section{Introduction}

An argument plays pivotal role in debating as it represents debater's point of view and attempt to persuade others of the validity of his or her opinion (Feez \& Joyce, 1998; Shulman, 2004). In delivering arguments, a debater may have various styles (Yuyun, 2014). The variety can be shown in the use of words showing the debater's attitude is so called a modality (Feez \& Joyce, 1998). As Halliday explains (2004:146-147), "Modality is used to temper, to qualify in some way, our propositions (modalization or epistemic modality) or proposals (modulation or deontic modality)." Modalization communicates any degree of probability (might, may, could...) or usuality (sometimes, usually, always). Meanwhile, modulation (deontic modality) regards degrees of obligation (necessity) in propositions and inclination or, as Halliday (1994:359) suggests, readiness, which could be seen as including willingness and also ability in proposals.
Besides, a debater may present an argument objectively or subjectively. The distinction between subjective and objective arguments is strictly speaking metaphorically (Halliday, 1994: 362). This distinction is then called an orientation which can be explicit and implicit variants (Halliday, 1994: 357). In debating, orientation refers to the speaker's strategies of expressing modality, or to the extent to which the speaker accepts responsibility for what $\mathrm{s} / \mathrm{he}$ is saying (Yuyun, 2010).

In regards to constructing implicit arguments (subjective and objective), debaters might use congruent realizations such as finite modals (can/could, may/might, will/would, should, ought to, must), adjuncts (possibly, probably, certainly, sometimes, usually, always, necessarily willingly, eagerly) and predicators (be allowed to, be supposed to, be obliged to, be willing to, be keen to, be determined to, be able to) (Martin, et al., 1997: 70). In this case, finite modals are subjective, adjuncts and predicators are objective. 
On the other hand, in order to construct explicit arguments (subjective and objective), debaters might use metaphorical realizations such as mental clause and attributive clause (Martin, et al., 1997: 70). The use of mental clause is expressed by cognitive verbs (I guess, I think, I know), affective verbs (I'm willing for..., I expect ...., I want...), and verbal group complex (I'd like to ..., I want to....). Attributive clause can be represented by the following expresessions: It is possible..., It is probable.., It is certain ..., It is unusual .., It is permitted .., It is expected .., It is necessary ..., It'd be lovely to ...., It is possible for...to.... .

Halliday \& Matthiessen (2004: 656) further say a nominalization is one of the most powerful resources for creating grammatical metaphor. It typically consists in the use of a nominal form to express the meaning of a process. Processes and properties are reworded metaphorically as nouns - as Things. For example, nominalization that could be used to express modality including possibility, probability, likelihood, certainly, unusualness, regularity, typicality, intention, desire, determination, need, obligation, regulation, compulsion and so on. By means of these nominalizations, modality is construed as an unquestionable fact i.e. modality is expressed explicitly with objectivity. Derewianka (1990: 76-78) adds that actions are often changed into "things" (nominalised) to make the argument sound more objective and to help structure the text.

Based on the background above, the present study, employing systemic functional analysis especially modality analysis, aims to reveal the subjectivity and objectivity of arguments in university-level debating.

\section{Method}

The subjects of this study were eight debaters in a final round of 2015 National University Debating Championship (NUDC) in Kopertis 3 Jakarta. Moreover, the data collection was done through a video recording. Then, the data were transcribed and analyzed using modality analysis (Yuyun, 2010). The data analysis was conducted as follows: dividing sentences carefully clause by clause, then, numbering the sentences and each clause, next, coding and classifying modality devices to ease the analysis, and finally, recapitulating modality devices.

\section{Findings and Discussions}

There are two elements that would be considered in measuring the subjectivity and objectivity of arguments among eight debaters including the total of modality orientation and manifestation.

There are four types of Orientation and Manifestation of Modality that occured in debating; they are implicitly subjective, implicitly objective, explicitly subjective, and explicitly objective.

\section{Implicit Subjective Modality}

The realization of modality through the use of Modal Operators is considered as subjective implicit forms. The debaters employed 165 subjective implicit arguments (34\%). The following examples will show how modality is expressed through Modal Operators (will/would, can, have to, and should).

\section{Government Whip (GW)}

35. (i) Now, an ... believers, none will be the wiser, (ii) nobody will continue to question them.

\section{Deputy Leader of Opposition (DLO)}

1. (i) The one who can win this debate (2) is the team that can prove (3) why the quality of religion that individual have will increase significantly.

In the sentences above, the speakers produced an expression of implicit modality of probability. In other words, the speakers are implicitly expressing the probability through modal operator will.

Furthermore, some speakers also used modal operator can to make an expression of implicit modality of ability as exemplified in the following sentence.

\section{Deputy Prime Minister (DPM)}

27. (i) Why don't encourage people (ii) because now is the trend to make people criticize their 
religion (iii) and some people can accept it for example progressive church.

The last examples employ modal operator have to and should that were used to express implicit modality of obligation.

\section{Deputy Prime Minister (DPM)}

47. (i) Is this allow the true feeling of people,

(ii) because they continue to have, (iii) because the church tells them (iv) you have to forbid the white people, ( $v$ ) because that's what God wants you to have.

\section{Member of Opposition (MO)}

14. (i) All I can see is that, (ii) you know (iii) what all kafir should die, (iv) that is my first perception and (v) only after a Muslim explained to me that (vi) that is not the case (vii) an Islam is actually a religion of peace.

As seen in Chart 1, Member of Government (Speaker \#3 of Government Team) has the highest percentage $(22 \%)$ in delivering her subjective argument implicitly. Then, it is followed by Government Whip (21\%), Leader of Opposition (14\%), Member of Opposition (12\%), Prime Minister (10\%), Deputy Leader of Opposition (9\%), Deputy Prime Minister (8\%), and Opposition Whip (4\%). It means that Member of Government (Speaker \#3 of Government Team) is the most subjective debater. She emphasizes the subjectivity of her points of view indirectly. It is not an effective way as it remains unclear for other debaters. Therefore, more explanation is sometimes required.

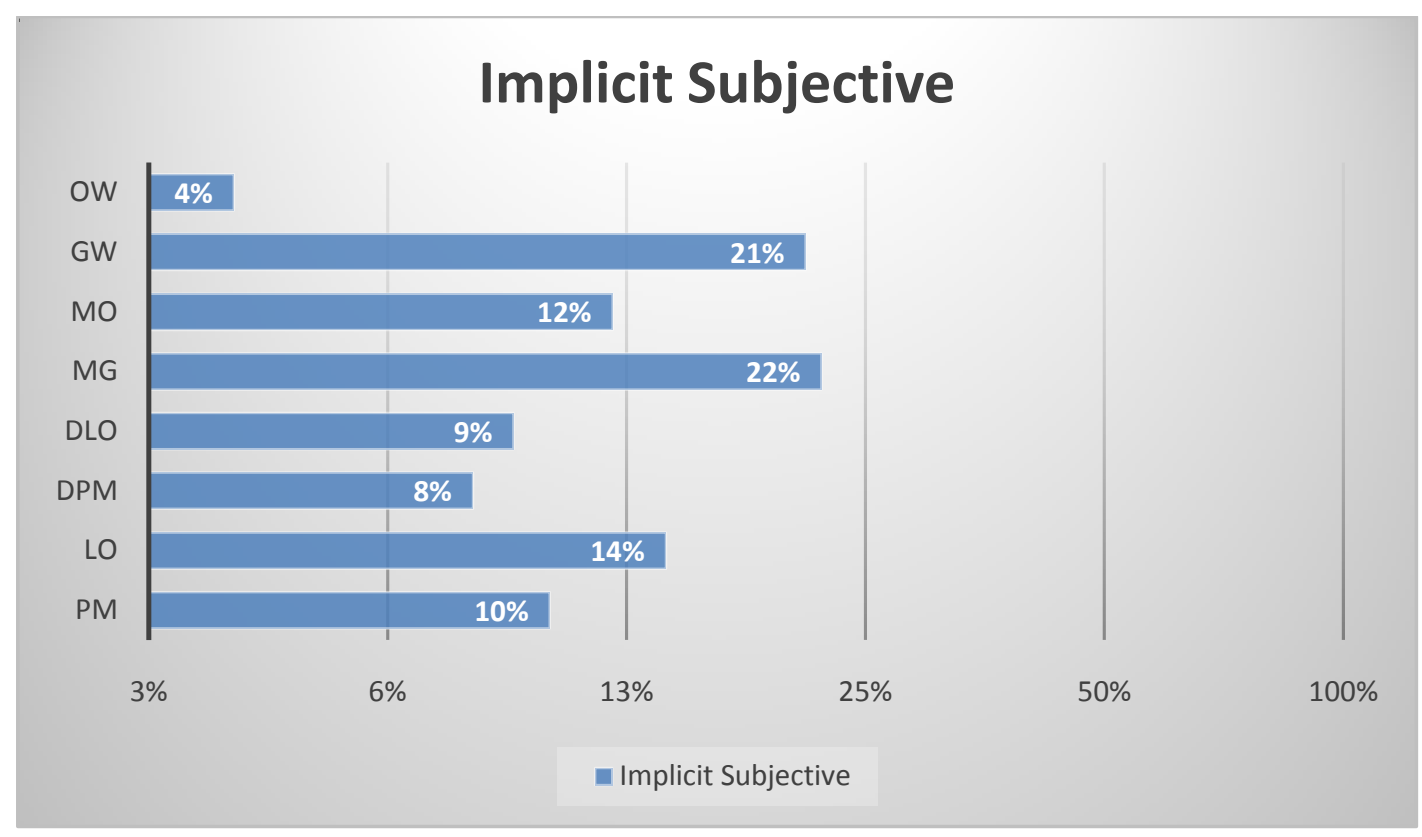

Chart 1: Comparative Percentages of Implicit Subjective Modality

\section{Implicit Objective Modality}

Implicit objective arguments occurred 132 times (27\%) in debating. This type of modality was expressed through mood adjunct and predicator. The following sentence was taken from Leader of Opposition (Speaker \#1 of Opposition Team):

\section{Leader of Opposition (LO)}

1. (i) Problem brought by Terry (ii) are actually problems that are really off-layers, (iii) right?
64. (i) We believe that spreading the good value is to introduce God (ii) and we believe that the introduction of God can only be done by the organized religion (iii) because, for example, we do preaching or missionary (iv) and we think that this is really important.

Really and actually, in the sentence above, were used by Leader of Opposition to show implicit objective arguments through mood adjunct. While, is to was a predicator, which functioned to show the speaker's implicit objective argument. 
The next example was taken from Government Whip (Speaker \#4 of Government Team):

\section{Government Whip (GW)}

28. (i) Maybe there's some radical people but at least on a smaller scale.
In this sentence, mood adjunct maybe is used to show implicit objective argument.

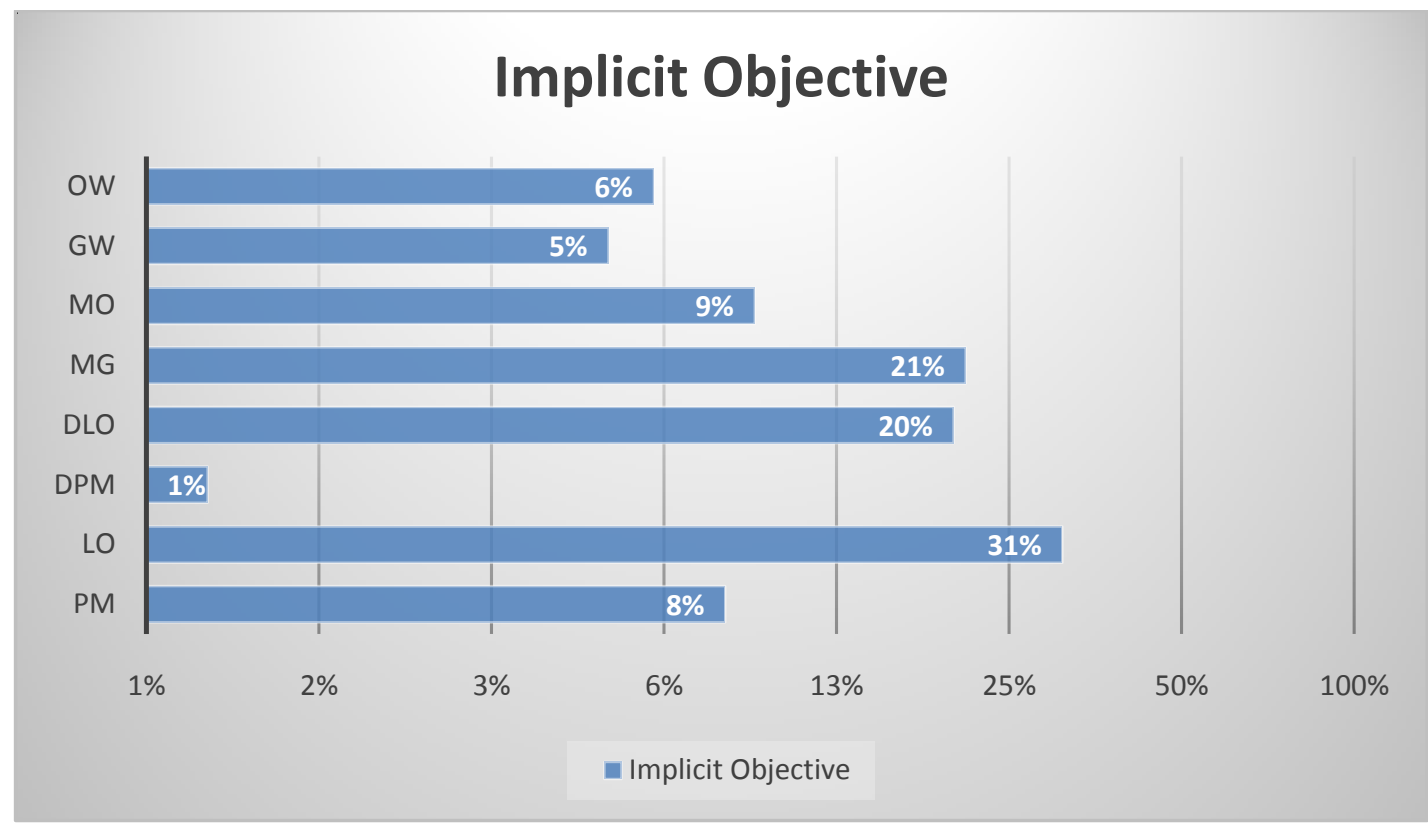

Chart 2: Comparative Percentages of Implicit Objective Modality

As seen on Chart 2, Leader of Opposition (Speaker \#1 of Opposition Team) has the highest percentage of using implicit objective modality (31\%). Meanwhile, the other debaters are around 1-21\%. This indicates that she tries to deliver her point of view objectively but still indirectly. It is not an effective way though since the debater cannot make his or her point of view appear to be a quality of the event itself because this objectification is not clear.

\section{Explicit Subjective Modality}

The next orientation and manifestation of modality is explicit subjective. The speakers employed 192 times (39\%); this was one of the most common employed in the debating. The following sentences were taken from some speakers in debating:

Prime Minister (PM)

2. (i) We think that assuming the existence of God, (ii) and assuming that religion is the best way for us to establish spiritual connection with God.

Government Whip (GW)

47. (i) Now, we believe that for decades, (ii) organized religion has done things, (iii) organized religion privatized force, laws and...(iv) discriminate, among each other for their knowledge, ladies and gentlemen.

\section{Member of Opposition (MO)}

29. (1) How do you ensure that is aligned with the society's need, (ii) what we know that there's always different subjectively by every religion?

16. (i) And if we see the bible and open the book of Daniel (ii) or you know what, (iii) the goal is actually same with the destruction of the humanity, (iv) is in order and humanity are all sinful, (v) there are a lot of people are all sinful, (vi) we will arbitrate them from the peace of the earth.

7. (i) Now we realize in bible and the quran, (ii) there is a necessary kind of commandment from God (iii) that told you (iv) that you have 
to safe your fellow teammates, eiger fellow neighbors.

These sentences employed we think, we believe, we know, we see, and we realize as subjective modality metaphors to express opinions. Here, debater's modality is realized as a separated clause, separated from the clause containing the proposition which is 'technically' being modalized. These projecting clauses are examples of explicit forms of modality and are forms of interpersonal grammatical metaphors. In explicit forms of modality, the speaker's opinion is not realized as a modal element within the clause (will, would, may, might, etc.) - which would be its more congruent realization - but is realized as a separate projecting clause (I/We think/believe/know/realize/see) - the less congruent form.

Moreover, the next examples were from Prime Minister (Speaker \#1 from
Government Team), Member of Opposition, and Leader of Opposition (Speaker \#3 and \#1 from Opposition Team):

\section{Prime Minister (PM)}

4. (i) Secondly, this is not a debate (ii) about whether we want to ban a religion or not.

Member of Opposition (MO)

1. (i) Ladies and gentlement, (ii) I believe (iii) that none of us can actually said that a religion, (iv) one religion is right are that one a religion as wrong.

Leader of Opposition (LO)

2. (i) Because not all churches, like what Prime Minister told you, are like that.

The verb want, said, and told were used to express the statements explicitly and the subject Prime Minister shows that the statements are subjective.

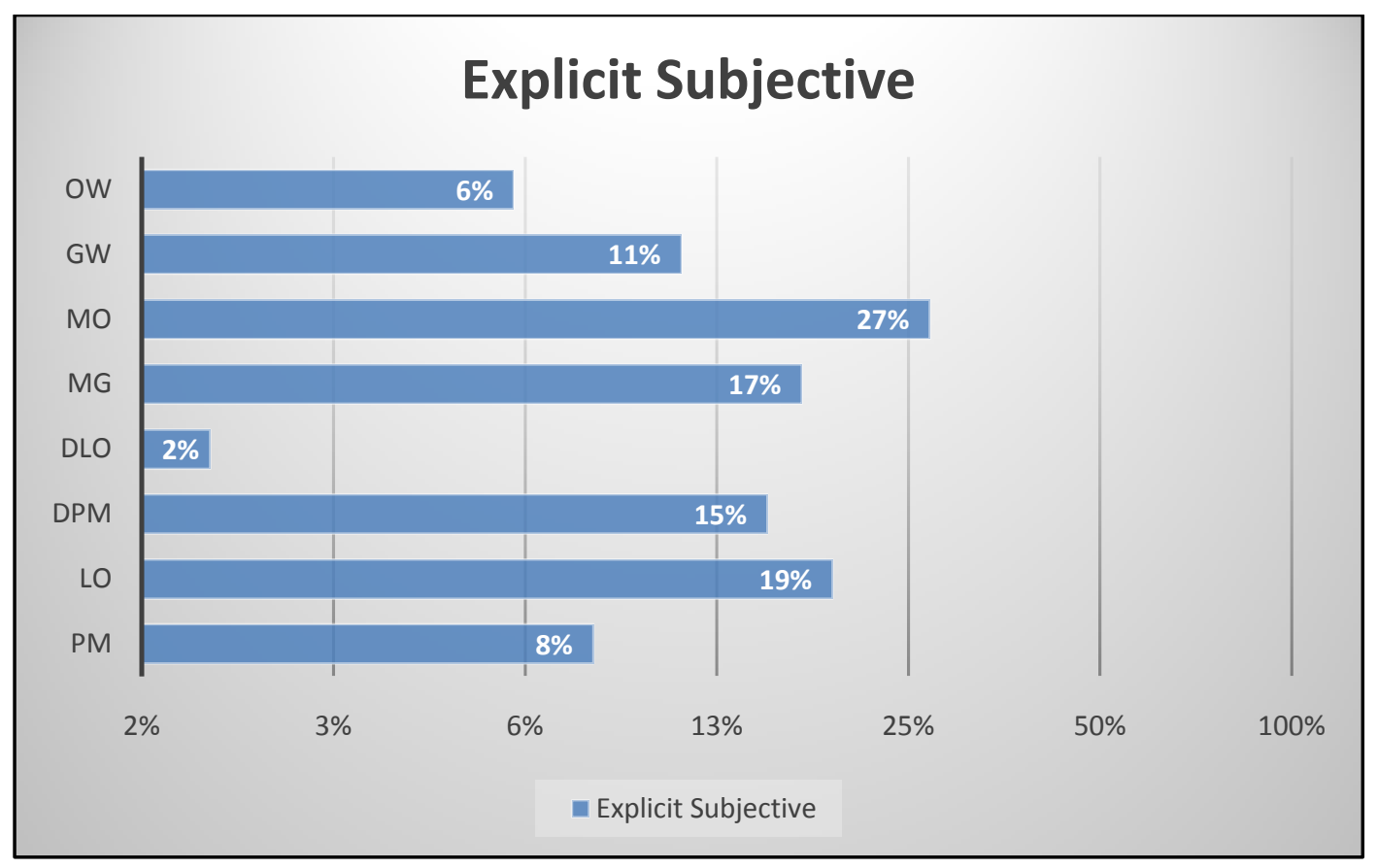

Chart 3: Comparative Percentages of Explicit Subjective Modality

Clearly shown in Chart 3 , as the most dominant participant that uses explicit subjective modality, Member of Opposition (Speaker \#3 of Opposition Team) shows her subjectivity prominently through some mental verbs (we know that..., we believe that..., we realize that...). Her prominent subjectivity shows her high assertiveness in delivering arguments (Yuyun, 2014). Especially, as Speaker \#3 of Opposition Team, she is responsible to extend the debate into a new area, introduce a couple of new arguments which make the case on his side more persuasive, and give a thing called 
"deeper analysis". In this case, Member of Opposition with her subjectivity and assertiveness has succeed adding something significant to the debate.

\section{Explicit Objective Modality}

The last type of orientation and manifestation of modality is explicit objective. This type of modality is expressed through attribute clause and nominalization. Halliday and Matthiessen (2004: 362) points out that it is one of the most effective way of creating objectivity. However, no debaters employed this modality orientation in the debate. This implies that all debaters prefer using subjective arguments to objective ones in debating.

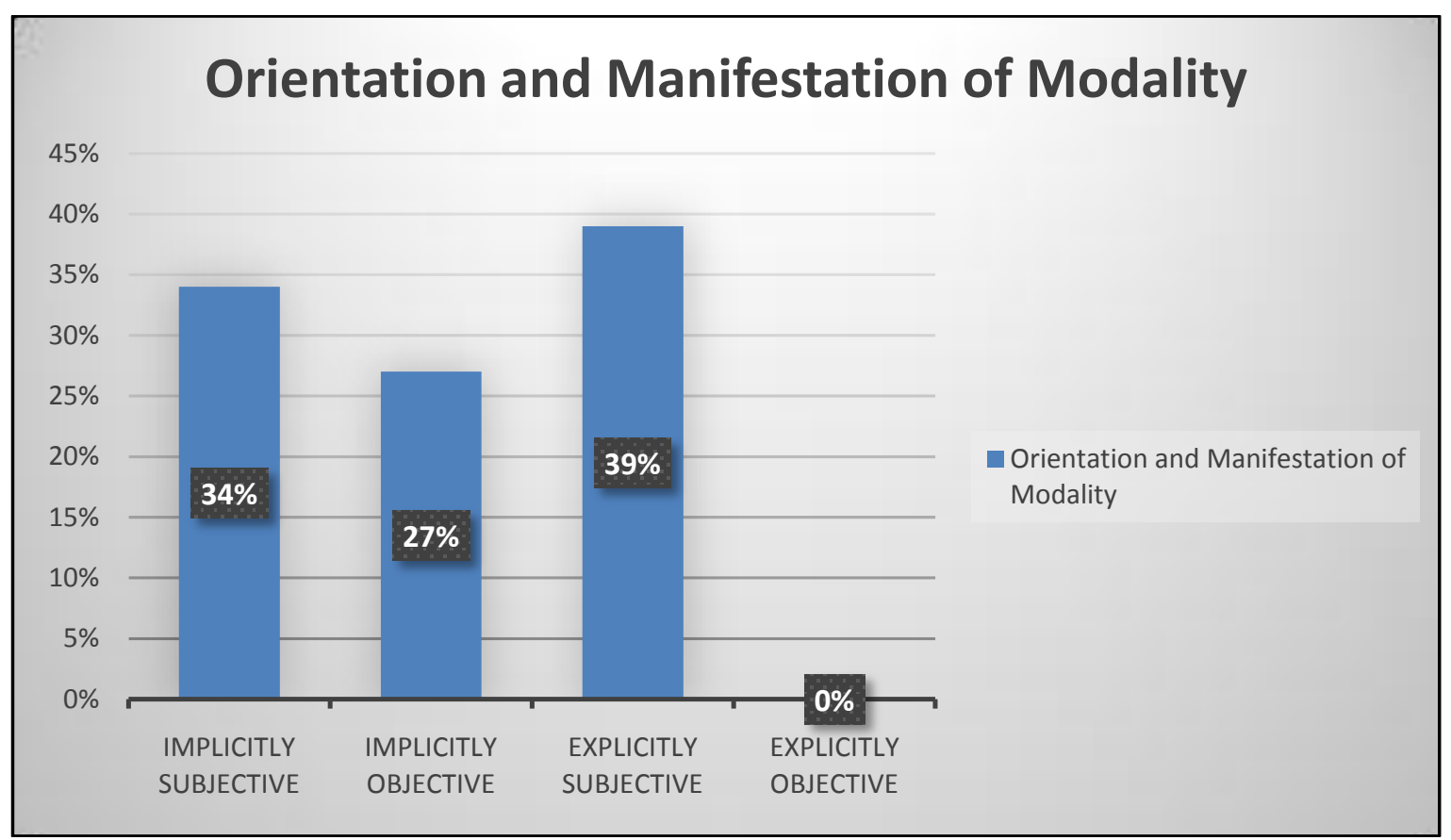

Chart 4: Comparative percentages of Orientation and Manifestation of Modality

A debater needs a variety of using modality in expressing his/her opinion in debating. In line with this, the debater can employ orientation and manifestation of modality. As seen on Chart 4, this present study confirms this point. The result shows, overall, there are 489 devices that occurred in all speakers. Explicitly subjective modality is the most common in all speakers with 192 occurrences (39\%). The second type that is mostly employed by the speakers is implicitly objective modality with 165 occurrences (34\%). The third is implicitly subjective modality with 132 occurrences $(27 \%)$. Eventually, there is no debater using explicit objective modality $(0 \%)$.
As previously mentioned, the dominant orientation and manifestation of modality is explicit subjective modality. This indicates that the debaters try to give the prominence to their point of view and to highlight the firmness of their attitude or belief so as to win the audience's support and understanding (Zhixiang, 2006; Yuyun, 2010). By using mental verbs (know, believe, think, realize, see, feel, want, tell, say, try), the debaters explicitly construct themselves as the source of the assessment, and to some extent, place their authority to assess at risk (Martin, 1995: 23). In line with this, Halliday \& Matthiessen (2004: 624) stated that explicitly subjective modality is the most effective way that used to give prominence to the speaker's own point of view since modality represents the speaker's 
angle; either on the validity of the assertion or on the rights and the proposal.

From the explanation above, it is inevitably that this present study reveals the dominant use of explicit subjective modality in delivering arguments. This explicit subjective modality implies that debaters prominently express their points of view to the debate.

\section{Conclusion}

Based on the main findings above, this study concludes that the debaters are more subjective in delivering their arguments in debating. Their subjectivity is prominently seen through the use of mental verbs such as know, believe, realize, see, think and affective verb such as want to. Besides, the subjectivity is implicitly shown through finite modals (would, will, can, should, have to, may, might, must).

\section{References}

Derewianka, B. Exploring How Texts Work, Sydney: PETA, 1990.

Feez, S., and Joyce, H. Writing Skills. Narrative and Nonfiction Text Types. Melbourne: Phoenix Education Pty. Ltd., 1998.

Halliday, M. A. K. An Introduction to Functional Grammar. New York: Edward Arnold, 1994.

Halliday, M.A.K. \& Matthiessen, C. An Introduction to Functional Grammar. Third Edition. London: Arnorld. 2004.

Martin, J.R. Interpersonal Meaning, Persuasion, and Public Discourse: Packing Semiotic Punch. Australian Journal of Linguistics 15 (1995), 33-67. 1995.
Martin, J. R., et al. Working with Functional Grammar. New York: Arnold, 1997.

McGregor, R. Analysing and Writing Arguments 1. Exploring and using the language of arguments. Melbourne: English Club, 2001.

Shulman, M. Thinking Critically: World Issues for Reading,Writing and Research. Ann Arbor: The Univerisity of Michigan Press, 2004.

Yuyun, Ignasia. Believe Me or I'll Loose: A Study of Assertiveness in A Debate Setting. Thesis. Bandung: Universitas Pendidikan Indonesia, 2010.

Yuyun, Ignasia. "A Study of Arguments in Senior High School Debate". Jurnal Penelitian. November 2010: 109-133.

Yuyun, Ignasia. "A Study of Assertiveness in A Debate Setting". Indonesian Journal of Applied Linguistics (IJAL). January 2014: 276-288.

Zhixiang, Z. A Functional Analysis of Interpersonal GM in Political Debates. Thesis. Yangzhou: Yangzhou University, 2006. 